\title{
Transoral Laser Excision of Schwannoma in Base of Tongue: A Case Report with Review of Literature
}

\author{
${ }^{1}$ Gaurav Ashish, ${ }^{2}$ Rajan S Sundereshan, ${ }^{3}$ Ajay Philip
}

\begin{abstract}
Shwannoma, better known as neurilemmomas, are benign, slow growing, usually solitary and encapsulated tumor, originating from Schwann cells of the nerve sheath. They are exceedingly rare in the base of tongue and, therefore, not immediately thought of as a differential diagnosis of oropharyngeal tumors. However, the key to the diagnosis lies in the histopathologic examination. A number of surgical approaches have been proposed for tongue base Schwannomas with varying degree of postoperative morbidity.

We report a case where a 19-year-old woman presented to us with progressive dysphagia, occasional dysarthria, and was found to have a large tongue base lesion. Diagnosis was confirmed by imaging studies and biopsy. Transoral laser assisted excision of the tumor was done. Histologic identification of Antoni $A$ and $B$ areas along with strong and diffuse staining with S-100 stain confirmed the diagnosis of Schwannoma.
\end{abstract}

Keywords: Antoni A and B, Schwann cells, Schwannoma, Tongue, Verrucay bodies.

How to cite this article: Ashish G, Sundereshan RS, Philip A. Transoral Laser Excision of Schwannoma in Base of Tongue: A Case Report with Review of Literature. Int J Otorhinolaryngol Clin 2015;7(2):68-71.

\section{Source of support: Nil \\ Conflict of interest: None}

\section{INTRODUCTION}

Schwannomas can arise from cranial nerves, spinal nerves or the autonomic nervous system. An estimated 25 to $45 \%$ of all Schwannomas occur in the head and neck. ${ }^{1}$ Of these, approximately 1 to $12 \%$ occurs intraoral with the tongue being one of the least involved sites. ${ }^{2}$

Schwannomas remain asymptomatic unless they attain appreciable size. They almost never undergo malignant transformation and do not show recurrence if completely excised. ${ }^{3}$

\footnotetext{
${ }^{1}$ Postgraduate Registrar, ${ }^{2}$ Assistant Professor, ${ }^{3}$ Senior Resident

${ }^{1}$ Department of ENT and Head and Neck Surgery, Christian Medical College, Vellore, Tamil Nadu, India

${ }^{2,3}$ Department of ENT, Christian Medical College, Vellore, Tamil Nadu, India

Corresponding Author: Gaurav Ashish, Postgraduate Registrar, Department of ENT and Head and Neck Surgery Christian Medical College, Vellore, Tamil Nadu, India, Phone: 9629329361, e-mail: gauravashish05@gmail.com
}

We present a case of a tongue base Schwannoma which was completely extirpated with a carbon dioxide laser transoral. The patient experienced virtually no morbidity from the use of the laser. Whilst various ways of treatment have been proposed yet transoral laser excision has rarely been used effectively.

\section{CASE REPORT}

A 19-year-old female was referred to our department with persistent globus sensation in the throat difficulty with articulation and occasional paresthesias at the base of the tongue over a period of 3 years. She had no other significant medical history.

Oropharyngeal examination revealed a $3 \times 2 \mathrm{~cm}$ large, non-exophytic lesion at the tongue base on the left-side (Fig. 1), not compromising the airway. The lesion was firm and non tender on palpation. The rest of his oropharyngeal and neck examination was normal.

Enhanced magnetic resonance imaging (MRI) showed a well-delineated mass in sagittal and axial T2-weighted images. Post contrast; axial T2-weighted image demonstrated a heterogeneous enhancement (Figs 2A and B).

Fine needle aspiration cytology was done preoperatively suggested a spindle cell lesion. The patient was planned for a transoral laser excision of the lesion. After orotracheal intubation, a Weerda bivalve distending laryngoscope was used to adequately expose the surgical field. The tumor was removed en bloc and measured approximately $5 \times 3 \mathrm{~cm}$ (Figs $3 \mathrm{~A}$ and B). Postoperative period was uneventful.

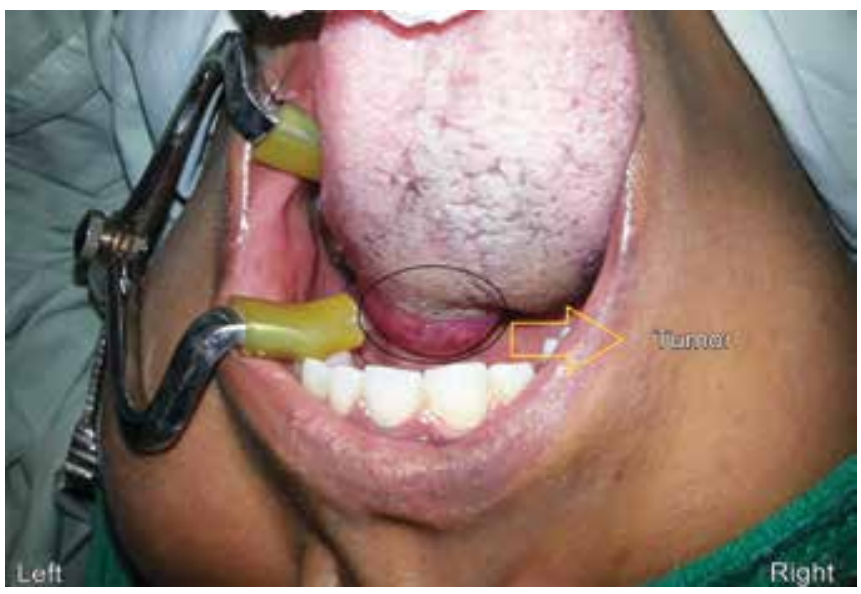

Fig. 1: Oropharyngeal examination showing the lesion in the tongue base 


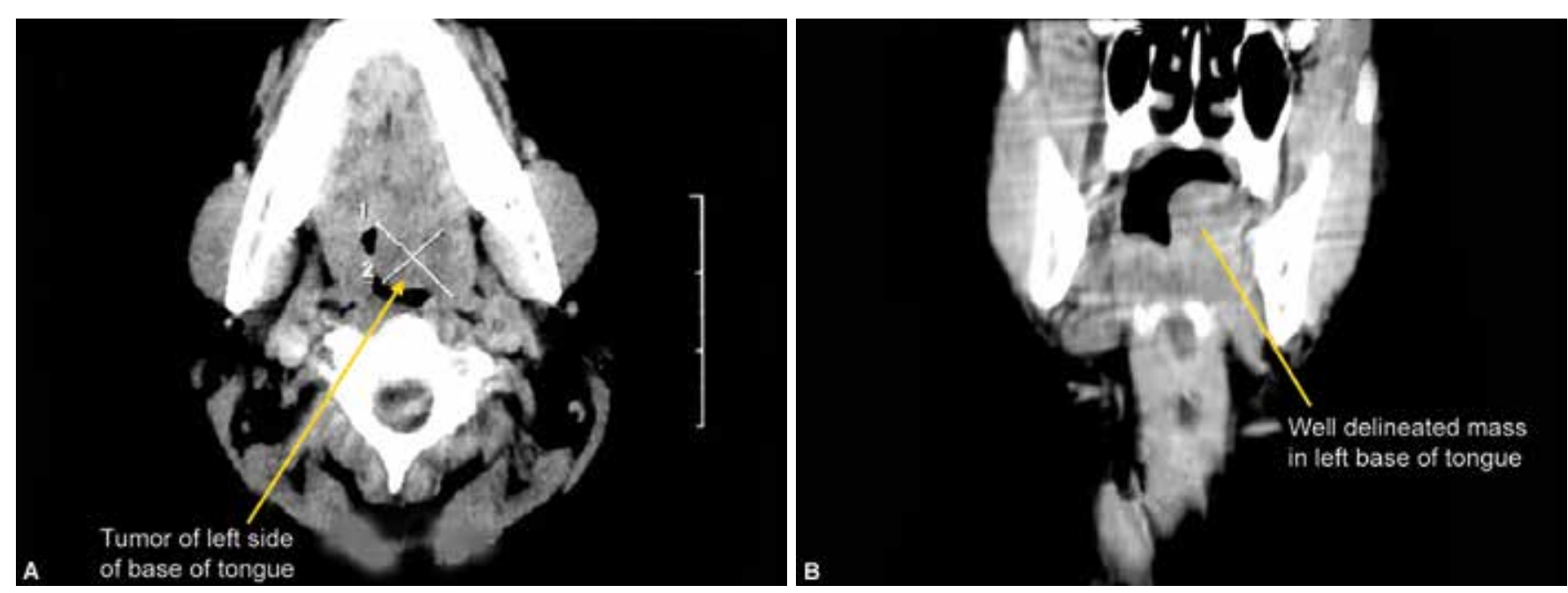

Figs 2A and B: Magnetic resonance imaging axial and sagittal view
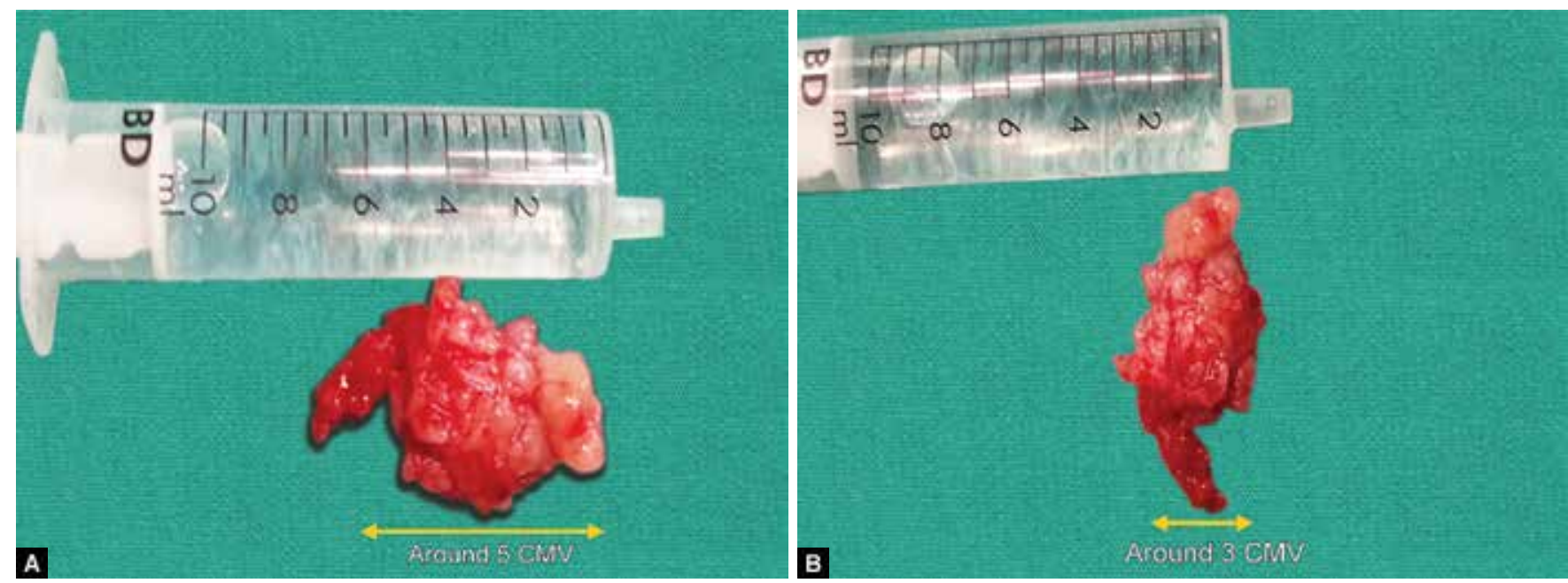

Figs 3A and B: Postoperative specimen

Histological examination of the specimen confirmed clear margins and fairly uniform spindle cells arranged in a loose myxoid pattern. There were cellular areas in which the nuclei were arranged in a palisaded pattern. The appearance was consistent with a benign Schwannomas of Antoni type A (Fig. 4). Immunocytochemical staining showed positive immunoreactivity for S-100 protein (Verocay bodies) thus, confirming the diagnosis (Fig. 5). She was followed up 3 months later where clinical examination revealed no evidence of residual or recurrent disease.

\section{DISCUSSION}

Schwannomas are rare tumors of the oral cavity, and is often a slow growing benign tumor of the nerve sheath (from Schwann cells). It was first described by Verocay in $1908 .^{4}$

In majority of the intraoral lesions, it is impossible to differentiate between tumors of the lingual, hypoglossal and glossopharyngeal nerves. ${ }^{5}$
Lingual Shwannoma affects commonly the age group between the first and the fourth decade and has no gender predisposition. In the tongue, two-thirds of cases involve the oral portion, and only about one-third involve the base. ${ }^{6}$

These are usually symptomless until they attain a significant size, however, some patients present with dysphagia, pain, swelling, fasciculation's, loss of tongue control, weight loss and even difficulty in breathing. ${ }^{7}$

Magnetic resonance imaging is the imaging modality of choice for Schwannomas; however, computed tomography (CT) shows early bone invasion if any. On CT, they are be well-circumscribed, homogeneous masses which enhance variably with contrast. ${ }^{8}$

Two growth patterns, namely Antoni A and B types are characteristic of Schwannomas. Antoni A pattern is highly cellular and composed of elongated Schwann cells, which are closely packed in a palisading arrangement. On the contrary, Antoni B areas are composed of elongated Schwann cells arranged in a less dense pattern. Between 


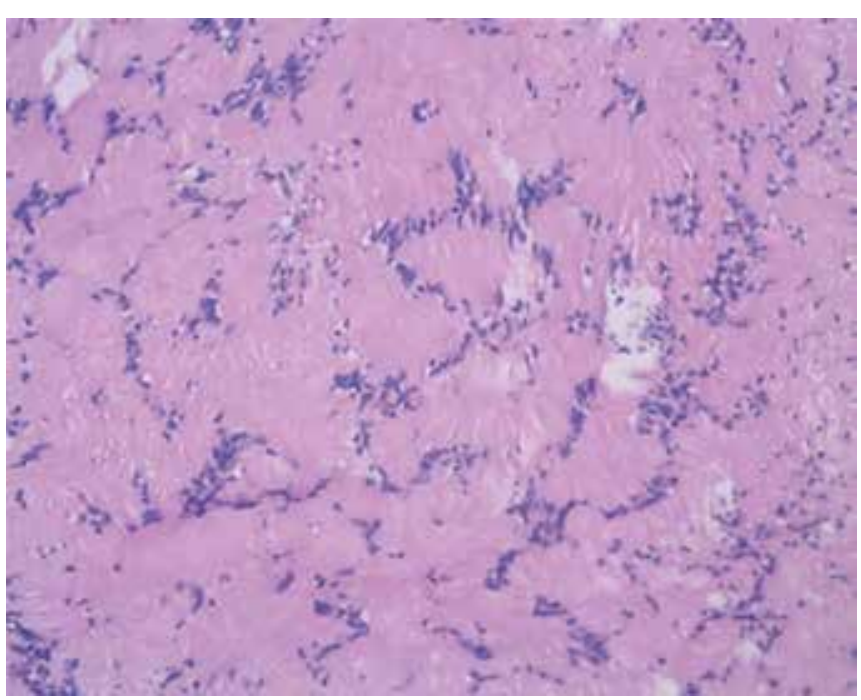

Fig. 4: Hematoxylin and eosin

these palisades are regions that are devoid of nuclei termed Verocay bodies, named after the Verocay who first described Schwannomas. ${ }^{9}$ These patterns are of only pathological significance and have no clinical correlation. The positive immunohistochemistry of S-100 and Leu 7 is a hallmark feature of the Schwannomas. ${ }^{10}$

The differential diagnosis mandates inclusion of neurofbromas, granular cell tumors, irritation fibromas, leiomyomas, rhabdomyomas, hemangiomas, lymphangiomas, lipomas, dermoid cysts, lipomas, lingual thyroid, pyogenic granulomas, and benign salivary gland tumors. ${ }^{11}$

The risk of malignant transformation of head and neck Shwannoma varies from 8 to $10 \%$, however, very rarely malignant transformation of tongue lesions have been reported. ${ }^{12}$

Surgical management of a Shwannoma affecting the tongue base is challenging, because of limited access, and that surgery may affect the second stage of swallow. During surgery, tumor size and operative exposure are the major variables.

Schwannomas located at the base of the tongue are usually treated by cervical access (transhyoid or submandibular) or rarely via transoral $\mathrm{CO}_{2}$ laser excision.

Use of transoral $\mathrm{CO}_{2}$ laser attached to an operating microscope via a micromanipulator allows the surgeon to have a precise magnified view of the tumor and overcomes the problems like excessive bleeding and inaccessible sites for conventional instruments. ${ }^{13}$

The $\mathrm{CO}_{2}$ laser (wavelength of $10,600 \mathrm{~nm}$ ) cuts by superficial tissue vaporization. The beam has sharply defined edges, hence increasing the precision of excision. Small blood vessels $(<0.5 \mathrm{~mm})$, are sealed off due to the vaporisation effect of the laser providing a relative dry field. Other lasers, (Argon, KTP and Nd: YAG,) may also

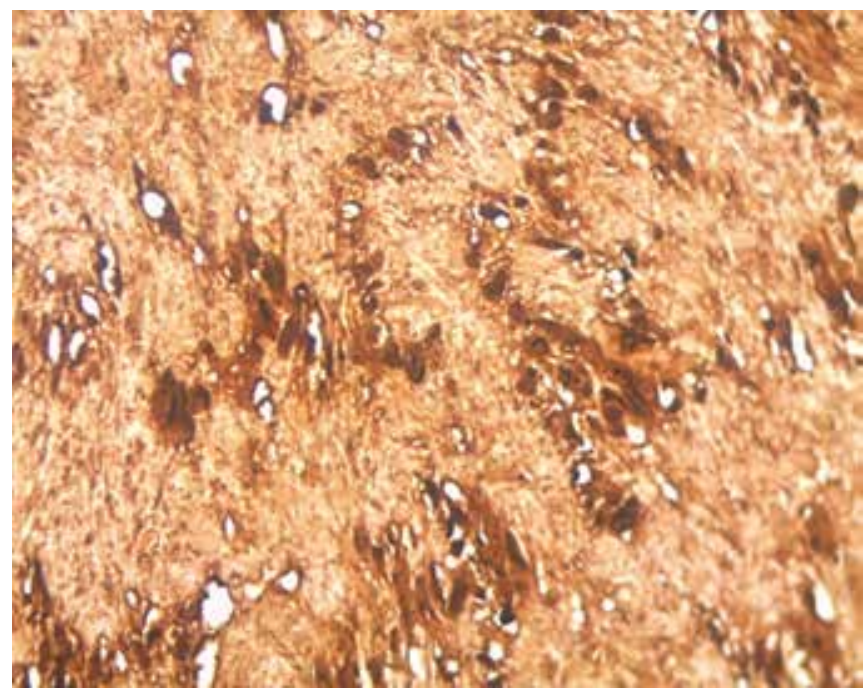

Fig. 5: S-100 positivity

be used, but interfere with the view of the lesion (as they require a fiberoptic cable) and shorter wavelengths leading to greater tissue penetration and damage limits their role in tongue base lesions. ${ }^{13}$

However, standard precautionary measures should be always followed to avoid any laser associated airway fire.

Total excision is associated with an excellent prognosis and recurrence is seen only with incomplete removal.

\section{CONCLUSION}

In summary, we have demonstrated a novel use of transoral $\mathrm{CO}_{2}$ laser in treating Shwannoma of the tongue base. Complete curative excision of the lesion was achieved with virtually no morbidity. The benefits of $\mathrm{CO}_{2}$ laser surgery in oropharyngeal surgeries in terms of organ and function preservation, less postoperative complications, shorter hospital stay, should be widely accepted for such tongue base lesions.

\section{REFERENCES}

1. Katz AD, Passy V, Kaplan L. Neurogenous neoplasms of major nerves of face and neck. Arch Surg Chic Ill 19601971 Jul;103(1):51-56.

2. Hatziotia JC, Asprides H. Neurilemoma (Schwannoma) or the oral cavity. Oral Surg Oral Med Oral Pathol 1967 Oct;24(4): 510-526.

3. Chiapasco M, Ronchi P, Scola G. Neurilemmoma (Schwannoma) of the oral cavity: a report of two clinical cases. Minerva Stomatol 1993 Apr;42(4):173-178.

4. Mosharrafa TM, Kuppersmith RB, Porter JP, Donovan DT. Pathologic quiz case 1: malignant peripheral nerve sheath tumor of the ethmoidal sinus. Arch Otolaryngol Head Neck Surg 1997 Jun;123(6):654, 656-657.

5. Dreher A, Gutmann R, Grevers G. Extracranial Schwannoma of the ENT region: review of the literature with a case report of benign Schwannoma of the base of the tongue. HNO 1997 Jun;45(6):468-471. 
6. Lira RB, Gonçalves Filho J, Carvalho GB, Pinto CA, Kowalski LP. Lingual schwannoma: case report and review of the literature. Acta Otorhinolaryngol Ital 2013 Apr;33(2):137-140.

7. Cohen M, Wang MB. Schwannoma of the tongue: two case reports and review of the literature. Eur Arch Otorhinolaryngol 2009 Nov;266(11):1823-1829.

8. Beggs I. Pictorial review: imaging of peripheral nerve tumours. Clin Radiol 1997 Jan;52(1):8-17.

9. Lollar KW, Pollak N, Liess BD, Miick R, Zitsch RP 3rd. Schwannoma of the hard palate. Am J Otolaryngol 2010 Apr; 31(2):139-140.
10. Cherrick HM, Eversole LR. Benign neural sheath neoplasm of the oral cavity: report of thirty-seven cases. Oral Surg Oral Med Oral Pathol 1971 Dec;32(6):900-909.

11. Nelson W, Chuprevich T, Galbraith DA. Enlarging tongue mass. J Oral Maxillofac Surg 1998 Feb;56(2):224-227.

12. Piatelli A, Angelone A, Pizzicannella G, Piatelli M. Malignant schwannoma of the tongue: report of a case and review of the literature. Acta Stomatol Belg 1984 Nov;81(3):213-225.

13. Mehrzad H, Persaud R, Papadimitriou N, Kaniyur S, Mochloulis G. Schwannoma of tongue base treated with transoral carbon dioxide laser. Lasers Med Sci 2006 Dec; 21(4):235-237. 